\title{
MODEL DAN STRATEGI PENYUNTINGAN DI PENERBITAN UNS PRESS SEBAGAI PENOPANG EKSISTENSI BAGI DUNIA KEPENULISAN
}

\author{
Yusuf Cahyo Saputro \\ FKIP Universitas Sebelas Maret \\ Surel: yusuf24@student.uns.ac.id
}

\begin{abstract}
Technical Implementation Unit for Publishing and Printing of Sebelas Maret University or better known as UNS Press is one of the supporting units of Sebelas Maret University which functions to carry out the publishing function. UNS Press is committed to positioning itself as an independent, professional, strict standard, proven quality, and at a relatively low cost. The ability to edit is qualified and the quality of quality publishing becomes the main pillar in supporting the existence of Indonesian writers. This study aims to find out how the role of publishers and editors in the world of writing. The publication under study was UNS Press. UNS Press is a printing and publishing agency located on the UNS central campus. With the publication and printing of the UNS Press, it is expected to support the existence of Indonesian writers.
\end{abstract}

Keyword: editing, publishing, and existence

\begin{abstract}
Abstrak: Unit Pelaksanaan Teknis Penerbitan dan Percetakan Universitas Sebelas Maret atau yang lebih dikenal dengan nama UNS Press adalah salah satu unit penunjang Universitas Sebelas Maret yang berfungsi melaksanakan fungsi penerbitan. UNS Press berkomitmen untuk memosisikan diri sebagai penerbit mandiri, profesional, standart ketat, kualitas teruji, dan dengan biaya yang relatif murah. Kemampuan menyunting yang mumpuni dan kualitas penerbitan yang berkualitas menjadi pilar utama dalam menunjang eksistensi penulis Indonesia. Penelitian ini bertujuan untuk mengetahui bagaimana peran penerbit dan penyunting dalam dunia kepenulisan. Penerbitan yang diteliti adalah UNS Press. UNS Press adalah lembaga percetakan dan penerbitan yang berada di kampus pusat
\end{abstract}


UNS. Dengan adanya penerbitan dan percetakan UNS Press maka diharapkan dapat mendukung eksistensi penulis Indonesia.

Kata kunci: penyuntingan, penerbitan, dan eksistensi

\section{PENDAHULUAN}

\section{Lembaga Perguruan Tinggi}

turut berperan dalam menyiapkan tenaga ahli di bidangnya. Salah satu persiapannya yaitu membekali keterampilan kognitif mahasiswa dengan ilmu yang teoretis. Persiapan tidak cukup hanya dibekali dengan teori di meja kuliah. Landasan yang kita ketahui bahwa ilmu teori yang dipelajari di bangku kuliah hanya $20 \%$ saja, $80 \%$ yang menentukan adalah sikap dan keterampilan sarjana. Seperti yang telah kita ketahui bahwa ada aspek afektif (sikap) dan psikomotorik. Dua karakteristik tersebut membutuhkan praktik langsung di lapangan maupun kehidupan sehari-hari. Fakta yang terjadi dewasa ini, banyak sekali lulusan sarjana yang masih mencari dan mengantri pekerjaan. Kesimpulan yang dapat diambil yaitu sarjana bukanlah jaminan untuk dapat segera menempati pos pekerjaan sesuai dengan keahlian yang dipelajarinya di Perguruan Tinggi.
Indonesia setiap tahunnya mencetak ribuan lulusan yang bergelar sarjana. Secara tidak langsung, ketersediaan lapangan pekerjaan dengan ribuan lulusan memiliki perbandingan yang tidak linier, sehingga angka pengangguran pun akan meningkat. Pelajaran yang dapat dijadikan refleksi serta koreksi untuk Perguruan Tinggi ialah kurangnya menyiapkan kompetensi mahasiswa dalam bidang yang ditekuninya, karena ilmu bangku kuliahan saja tidak cukup untuk menghadapi persaingan dalam karier masa depan. Namun ada yang berbeda dengan Program Studi Pendidikan Bahasa Indonesia FKIP UNS, Program Studi ini menginisiasi untuk memecahkan persoalan tingginya angka pengangguran setelah menyelesaikan belajar di Perguruan Tinggi yaitu dengan adanya mata kuliah pilihan yang terdiri dari penyiaran, penyuntingan, dan jurnalistik. 
Penyuntingan merupakan kegiatan menyiapkan naskah siap cetak atau siap terbit dengan memperhatikan segi sistematika penyajian, isi, dan bahasa (menyangkut ejaan, diksi, dan struktur kalimat), (Eneste, 2017:8). Jurnalistik publik adalah suatu model peliputan berita yang bertujuan sesuai dengan misi negara yakni mendorong kehidupan publik/warga negaranya menuju kesejahteraan dan mencari konsensus untuk memecahkan permasalahan di masyarakat.

Alumni Pendidikan Bahasa Indonesia dipersiapkan untuk mencetak calon guru bahasa Indonesia. Selain itu juga diberikan keterampilan dengan keahlian yang diambil pada mata kuliah pilihan. Secara tidak langsung dengan adanya mata kuliah pilihan ini, program studi Pendidikan Bahasa Indonesia memberikan solusi akan tingkat pengangguran yang tinggi. Selaras dengan visi program studi Pendidikan Bahasa Indonesia sebagai pusat pendidikan dan pengembangan pendidikan bahasa dan sastra Indonesia yang mampu menghasilkan tenaga kependidikan yang memiliki keunggulan, kemandirian, daya saing, berkarakter kuat, dan cerdas.

Teknologi informasi dan komunikasi merupakan salah satu sarana prasarana untuk menyajikan informasi yang berbentuk struktur kelembagaan dan nilai-nilai sosial yang dikumpulkan, disimpan, diolah, dan dipertukarkan sehingga memungkinkan terjadinya persepsi dan atau tindakan (Bayquni, dkk., 2015:71).

UU penyiaran mendefinisikan penyiaran merupakan kegiatan pemancarluasan siaran melalui sarana pemancar dan/atau sarana transmisi di darat, di laut, dan di antariksa dengan menggunakan spektrum frekuensi radio (sinyal radio) yang berbentuk gelombang elektromagnetik yang merambat melalui udara, kabel, dan atau media lain untuk dapat diterima secara serentak dan bersamaan oleh masyarakat dengan perangkat penerima siaran (Budiman, 2015:11).

Untuk itu, pembekalan keterampilan pada mata kuliah pilihan juga harus mendapatkan dukungan dengan mitra melaului kerja sama. Hal ini disebabkan 
Pendidikan Bahasa Indonesia belum memiliki laboratorium khusus yang memadai untuk praktik seputar mata kuliah pilihan (penyuntingan). Untuk itu, dibutuhkan kegiatan magang pada lembaga yang bekerja sama (perusahaaan yang bergerak di bidang penerbitan).

Magang pendidikan adalah
suatu sarana bagi pelajar untuk
menambah ilmu pengetahuan dan
mengaplikasikan ilmu yang telah
diperoleh dengan menerapkannya secara langsung di dunia kerja (Indrakusuma, 2016:32). Pengalaman praktik di tempat magang akan mengasah keterampilan mahasiswa dalam menerapkan ilmu yang didapatkan. Pembelajaran yang bersifat aplikatif didapatkan ketika magang. Adapun penilaian yang akan diberikan mencakup beberapa aspek sebagai berikut: (1) kedisiplinan, (2) kreativitas, (3) kerja sama tim, (4) produktivitas, (5) kualitas kerja, dan (6) nilai akhir/akumulatif.

Kemampuan yang dapat ditunjukkan selain menyunting dan dapat diasah mahasiswa adalah menulis. Menulis adalah kemampuan yang harus dilakukan secara kontinu dan berkesinambungan. Ini berarti bahwa untuk menjadi penulis, seseorang harus melakukan kegiatan menulis secara terus-menerus. Intensitas menulis akan menentukan apakah seseorang memiliki ketajaman yang baik atau tidak terhadap permasalahan yang ditulisnya. Menulis juga dilakukan dengan melibatkan emosional manusia sebagai sebuah potensi (Bird, 2001:32). Bahasa dalam dunia kepenulisan sangat penting, karena salah satu fungsi bahasa adalah sebagai alat menyampaikan informasi dan pikiran-pikiran dari seseorang kepada orang lain (Fasold dalam Saddhono, 2006:3).

Seorang penulis tentunya membutuhkan seorang penyunting dan perusahaan penerbitan untuk menerbitkan karya-karyanya. Menulis merupakan salah satu kegiatan komunikasi berupa penyampaian pesan secara tertulis kepada orang lain. Hartono, Sumarwati, dan Mulyana, (2014: 465) berpendapat bahwa menulis merupakan bagian dari alat komunikasi. Menulis tak bisa 
dipisahkan dari kehidupan seharihari. Melalui kegiatan menulis seseorang dapat menuangkan pikiran, ide, maupun perasaannya dalam bentuk tulisan (Ahsin, 2016: 159). Salah satu kegiatan menulis yaitu menulis artikel ilmiah. Keterampilan menulis merupakan hal yang sangat penting. Mundziroh, Sumarwati, dan Saddhono (2013: 4) berpendapat bahwa menulis merupakan kegiatan komunikasi, sama dengan komunikasi lisan, pesan yang tepat dan efektif akan memudahkan penerima pesan sebelumnya. Keterampilan menulis adalah kemampuan mengekspresikan pikiran melalui lambang-lambang tulisan (Sari, Saddhono, dan Suyitno, 2014: 540). Dengan adanya penyuntingan dan penerbitan, maka sangatlah berpengaruh bagi eksistensi para penulis di Indonesia.

Kegiatan magang ini memiliki tujuan umum dan khusus. Pelaksanaan magang sebagai salah satu bentuk aplikasi terhadap Tri Darma Perguruan Tinggi terutama dalam bidang pengabdian masyarakat dan juga untuk mengetahui gambaran dunia kerja seorang editor. Adapun tujuan khusus, sebagai berikut:

1. Memenuhi tugas akhir mata kuliah Penyuntingan III dengan menjalin kerja sama dan kemitraan antara perguruan tinggi dengan lembaga-lembaga industri dan perusahaan percetakan dan penerbitan di Surakarta;

2. Mengimplementasikan teoriteori yang telah didapatkan mahasiswa selama masa perkuliahan;

3. Memberikan kesempatan kepada mahasiswa untuk berlatih dan mempraktikkan ilmu yang diterima selama perkuliahan dalam bidang profesi nonkependidikan;

4. Memberikan bekal keahlian bidang penyuntingan sebagai alternatif pilihan karier di masa depan; dan

5. Melatih mental mahasiswa di lapangan kerja kehidupan yang sesungguhnya.

Alasan kekuatan yang dimiliki UNS Press antara lain karena banyaknya penghargaan dan prestasi 
yang telah dicapai dalam dunia penerbitan. Pada tahun 2016, UNS Press meraih penghargaan tingkat nasional dalam melaksanakan Undang-Undang (UU) Nomor 4 tahun 1990 tentang Serah Simpan Karya Cetak dan Karya Rekam. Penghargaan diberikan Kepala Perpustakaan Nasional RI, Muhammad Syarif Bando kepada Kepala Penerbit dan Percetakaan UNS Press, Bambang Prawiro MM di Jakarta. Ini sebagai bukti UNS Press tidak kalah dengan percetakan di Perguruan Tinggi lain. Keberadaan UNS Press menjadi sangat diperhitungkan sebagai penerbit dan percetakan yang baik, professional dan taat UU No 4 tahun 1990.

Unit Pelaksanaan Teknis Penerbitan dan Percetakan Universitas Sebelas Maret atau yang lebih dikenal dengan nama UNS Press adalah salah satu unit penunjang Universitas Sebelas Maret yang berfungsi melaksanakan fungsi penerbitan. UNS Press didirikan bertujuan untuk menerbitkan buku, jurnal, majalah, dan produk penerbitan lainnya. UNS Press menerbitkan karya ilmiah, terutama buku, dengan pengarang yang bisa berasal dari UNS sendiri dan dari luar UNS, baik dari perguruan tinggi maupun dari luar perguruan tinggi. Produk yang bertalian dengan pendidikan, hasil simposium atau seminar, dan hasil penelitian. UNS Press berusaha menjaga mutu terbitannya, terutama mengenai isi dan bahasanya. Produksi UNS Press rutin dari tugas besar kantor pusat (rektorat UNS).

UNS Press berkomitmen untuk memosisikan diri sebagai penerbit mandiri, profesional, standart ketat, kualitas teruji, dan dengan biaya yang relatif murah. UNS Press berdiri pada tanggal 14 Agustus 1989 dengan SK Rektor No. 54/PT.40.D/89 tentang pembentukan Unit Pelaksana Teknis Penerbitan dan Percetakan Universitas Sebelas Maret. Tugas Utama UNS Press adalah melakukan kegiatan di bidang penerbitan dan pencetakan yang bersifat teknis, baik dengan buku maupun nonbuku. Sejak berdiri 22 tahun yang lalu, UNS telahberganti pimpinan sebanyak 3 kali, yaitu Dr. Sudiro Sutoto, Drs. A. Himawan, dan Drs. Y. Radiyono. Pada awal tahun 
2004 UNS mempunyai jabatan baru yaitu sekretaris yang dijabat oleh Kundharu Saddhono, S.S., M.Hum. dan kini dijabat oleh Dr. Sumarwati, M.Pd. UNS Press saat ini dipimpin oleh Bapak Budi Siswanto, S.Pd., M.Ars.

\section{METODE PENELITIAN}

Jenis penelitian yang digunakan pada penelitian ini adalah jenis penelitian kualitatif. Menurut Sukmadinata (2009:53) penelitian kualitatif adalah penelitian yang digunakan untuk mendeskripsikan dan menganalisis fenomena, peristiwa, aktivitas sosial, sikap, kepercayaan, presepsi, dan orang secara individual maupun kelompok. Metode penelitian yang berlandaskan pada filsafat postpositivisme, yang digunakan untuk meneliti pada kondisi obyek yang alamiah (sebagai lawannya adalah eksperimen) di mana dalam penelitian ini peneliti sebagai instrumen kunci.

\section{HASIL DAN PEMBAHASAN}

Banyak manfaat yang didapat dari kegiatan magang penyuntingan di UNS Press. UNS Press sangat mendukung adanya magang penyuntingan ini, sehingga pihak UNS Press dengan sepenuh hati selalu memberikan pembelajaran mengenai kegiatan menyunting. Kegiatan magang penyuntingan ini sebagai proses pembelajaran praktik dalam mengembangkan keterampilan menyunting secara optimal. Dengan adanya kegiatan magang penyuntingan ini, mahasiswa dapat menyalurkan ilmu yang kami terima pada perkuliahan sebelumnya.

Pengalaman dan tantangan yang didapatkan dalam kegiatan magang ini tidak lain sangat bermanfaat sebagai alternatif pilihan karier di masa depan dan juga menjadi bekal untuk menjadi seorang guru atau dosen Bahasa Indonesia. Untuk menjadi seorang penyunting yang profesional dan handal membutuhkan banyak sekali ilmu yang harus dikuasai. Penyunting juga harus memiliki ketelitian dan kecermatan serta mengikuti perkembangan ilmu pengetahuan terbaru sehingga dapat memberikan data yang sahih dengan wawasan yang luas.

Kelebihan dari UNS Press adalah tidak hanya mencetak dan 
menerbitkan, UNS Press juga melakukan pemasaran produk melalui divisi pemasaran. Buku yang telah disunting dan dicetak tidak sekadar untuk disimpan sendiri. Pihak UNS Press melalui divisi pemasaran berusaha untuk menarik konsumen dan menjual buku tersebut agar laku di khalayak umum.

1. Strategi Penyuntingan di UNS Press

Strategi penyuntingan yang diterapkan di UNS Press berfokus pada penguasaan tentang tata bahasa dan ejaan. Setiap penyunting atau editor di UNS Press dituntut untuk tepat dalam mengoreksi ejaan dan tata bahasa pada naskah, baik naskah buku yang bersifat ilmiah maupun buku fiksi.

Pedoman pokok yang digunakan selama proses menyunting adalah KBBI dan PUEBI. Kedua pedoman tersebut menjadi dasar untuk menentukan ejaan dan tata bahasa yang tepat digunakan dalam naskah. Seorang penyunting harus menguasai dan selalu berpegang pada kedua pedoman tersebut.
Penyuntingan naskah disebut juga editing naskah. Editing secara umum menurut Goodman dan Mc Grath (2003:5) diartikan sebagai kegiatan mengumpulkan, menyiapkan, dan mengatur materimateri untuk dipublikasikan. Editing juga memperbaiki, menghapus, atau mengurangi. Penyuntingan naskah meliputi penyuntingan bahasa dan ejaan diantaranya tanda baca, kalimat efektif, penyusunan daftar pustaka, kebakuan kata, penggunaan huruf kapital, pemilihan diksi, akronim, penulisan nama gelar, dan sebagainya. Pedoman Umum Ejaan Bahasa Indonesia dan KBBI digunakan sebagai acuan dan pedoman dalam menyunting naskah selama kegiatan magang. Ditinjau dari segi bahasa perlu diperhatikan tentang kalimat kalimat, keterpaduan antarparagraf dan kebenaran informasi pada naskah.

Faktor penyebab kesalahan berbahasa dalam karangan mahasiswa disebabkan oleh dua faktor, yakni faktor internal yang meliputi: (a) rendahnya motivasi, (b) perbedaan potensi,(c) kedekatan rumpun bahasa, dan faktor eksternal yang meliputi: (a) 
pembelajaran yang belum sempurna,

(b) masa belajar yang singkat (Saddhono, 2012:178)

\section{Gaya Selingkung UNS Press}

Gaya selingkung merupakan penyelarasan atau pembakuan dalam penyampaian informasi secara taat azas dengan memperhatikan jati diri dan ciri khas lembaga atau jurnal tertentu (Helianti dalam Suyono, 2015:74). Gaya selingkung UNS Press adalah sebagai berikut. Ukuran buku cetak UNS Press adalah A5 dengan ketentuan sebagai berikut.

A. Page setup

a. Ukuran margin Top 2,5 cm; Bottom $3 \mathrm{~cm}$; Left 2,25 cm; Right 2,25 cm.

b. Ukuran kertas width $16 \mathrm{~cm}$ dan height $25 \mathrm{~cm}$.

c. Layout, Header $1,5 \mathrm{~cm}$ (jarak judul buku di atas), Footer $2 \mathrm{~cm}$ (jarak halaman buku di bawah) dengan modus different odd and even.

B. Penggunaan font

a. Judul bab: Times New Roman 16 point, capital bold.

b. Judul sub bab: TNR 14 point, bold. c. Judul sub-sub bab: TNR 11 point, bold.

d. Teks isi: TNR 11 point.

e. Keterangan

gambar/tabel/diagram pada naskah: TNR 9 point, center, single spacing.

f. Header Arial 9 point bold.

g. Footer Arial 9 point bold.

h. Footnote TNR 9 point.

C. Penomoran dan pengaturan halaman

Format nomor: I, ii, iii, ... dan 1, 2, 3 tidak diperkenankan menggunakan bullet.

D. Format paragraf

E. Penulisan daftar pustaka

F. Urutan penulisan naskah

G. Urutan bagian buku

H. Penggunaan gambar pendukung

3. Tugas Penyunting

Di dunia penerbit buku di Indonesia, seorang penyunting naskah atau kopieditor lazim dianggap sebagai pembantu seorang editor. Naskah yang sudah disetujui penerbit untuk diterbitkan, mula-mula akan diserahkan kepada editor 
untuk disunting dari segi materi. Setelah itu naskah diserahkan kepada penyunting naskah untuk disunting dari segi kebahasaan (ejaan, diksi, struktur kalimat, dan lainlain).

Oleh karena itu, tugas penyunting naskah dapat diperinci sebagai berikut:

a. menyunting naskah dari segi kebahasaan (ejaan, diksi, struktur kalimat);

b. memperbaiki naskah dengan persetujuan penulis/pengarang;

c. membuat naskah enak dibaca dan tidak membuat pembaca bingung

(memperhatikan

keterbacaan naskah);

d. membaca dan mengoreksi cetak coba (pruf).

4. Peran Penyunting dalam Mendukung Kegiatan Kepenulisan

Peran seorang editor akan terus diperlukan selama karya tulis itu ada. Tidak ada seorang penulis pun yang hasil karyanya seratus persen benar atau sempurna meskipun sudah melakukan swasunting. Seorang penulis yang sekaligus editor pun, tetap hasil karyanya harus dibaca dan diedit terlebih dahulu oleh seorang editor. Secara profesional seorang penulis bukanlah seorang editor. Begitu juga sebaliknya, seorang editor bukanlah seorang penulis.

Peran editor sangat besar bagi penulis. Editor adalah rekan penulis dalam mewujudkan keinginannya dalam menerbitkan buku. Berikut beberapa peran editor di sebuah penerbit, yaitu.

a. Editor membantu penulis agar karyanya layak terbit dan layak baca.

b. Editor membantu penulis, terutama dalam hal kebahasaan, seperti ejaan, tata bahasa, pilihan kata, tanda baca, dan lain-lain.

c. Editor membantu penulis dalam menghasilkan karya yang berkualitas agar tulisan memiliki 
kohesi dan koherensi yang tepat, baik antarkalimat maupun antarparagraf. Bahkan, antarsubbab, judul, dan lain-lain.

d. Editor harus dapat meluruskan gagasan yang kurang tepat dan membicarakan atau mendiskusikannya

terlebih dahulu dengan penulis.

e. Editor harus dapat membuat naskah yang dieditnya bersih dari kesalahan sehingga menjadi lebih sistematis, mudah dibaca, mudah dipahami, dan mudah dimaknai.

f. Editor harus mampu menjembatani antara penulis dan penerbit. Jadi, mampu membedakan antara kepentingan bisnis dan kepentingan intelektual.

\section{PENUTUP}

`Berdasarkan penelitian dan pembahasan yang telah dilakukan dengan mencermati objek kajian maka, dapat diambil simpulan sebagai bahwa UNS Press merupakan tempat penerbitan sekaligus percetakan yang sangat banyak memberikan ilmu serta pengalaman bagi mahasiswa yang magang disana. Selain itu, UNS Press sangat berperan penting dalam eksistensi penulis di Indonesia. UNS Press merupakan salah satu penerbitan yang memiliki kualitas baik dengan strategi menyunting hingga menerbitkan yang baik. UNS Press berusaha menjaga mutu terbitannya, terutama mengenai isi dan bahasanya. UNS Press berkomitmen untuk memposisikan diri sebagai penerbit mandiri, profesional, standart ketat, kualitas teruji, dan dengan biaya yang relatif murah. Hal tersebut dapat dibuktikan melalui sumber daya manusia yang ada di UNS Press merupakan orangorang yang mumpuni dan profesional. Terdapat seleksi yang ketat untuk dapat bekerja di UNS Press. Tidak sembarang orang dapat bekerja disana. Pegawai UNS Press harus memiliki tingkat pendidikan yang tinggi yang benar-benar mengerti tentang dunia penerbitan dan 
percetakan. Kualitas yang baik dari UNS Press inilah yang dapat membantu para penulis dalam menerbitkan karya-karyanya agar dapat bermanfaat untuk semua orang.

Mata kuliah penyuntingan sering dipandang oleh sebagian mahasiswa tidak masuk dalam jurusan ini sebagai mata kuliah yang mudah, tidah menantang, dan menjadi hal yang sudah biasa dalam Bahasa Indonesia. Padahal untuk menjadi seorang penyunting handal dibutuhkan imu pengetahuan yang memadai, dipastikan kebenarannya, dan juga membutuhkan ketelitian dan kecermatan. Seorang penyunting tidak boleh bertindak asal-asalan terhadap naskah penulis sesuai dengan kode etik penyuntingan.

Pembekalan keterampilan pada mata kuliah pilihan juga harus mendapatkan dukungan dengan mitra melalui kerja sama. Hal ini disebabkan Pendidikan Bahasa Indonesia belum memiliki laboratorium khusus yang memadai untuk praktik seputar mata kuliah pilihan (penyuntingan). Untuk itu, dibutuhkan kegiatan magang pada lembaga yang bekerja sama (perusahaaan yang bergerak di bidang penerbitan). Pengalaman praktik di tempat magang akan mengasah keterampilan mahasiswa dalam menerapkan ilmu yang didapatkan. Pembelajaran yang bersifat aplikatif didapatkan ketika magang.

\section{DAFTAR PUSTAKA}

Ahsin, M. N. (2016). Peningkatan Keterampilan Menulis Karangan Narasi dengan Menggunakan Media Audiovisual dan Metode Quantum Learning. Jurnal Refleksi Edukatika, 6(6), 158171.

Bayquni, dkk. (2015). Pertukaran Informasi oleh Mahasiswa Jurusan Ilmu Jurnalistik Melalui Media Kompasiana. Jurnal Kajian Informasi dan Perpustakaan. 3 (1) 71.

Bird, C. (2001). Menulis dengan Emosional, Panduan Empatik Mengarang Fiksi. Bandung: Kaifa.

Budiman, A. (2015). Model Pengelolaan Digitalisasi 
Penyiaran Di Indonesia.

Politica, 6 (2) 111.

Eneste, P. (2017). Buku Pintar Penyuntingan Naskah.

Jakarta: Gramedia Pustaka Utama.

Goodman, R. \& Mc Grath, P.J. (2003) Editing Digital Video. New York : McGraw-Hill.

Hartono, F. S., Sumarwati, Mulyana, S. (2014). Penerapan Model Pembelajaran Kuantum Tipe Tandur untuk Meningkatkan Motivasi dan Kemampuan Menulis. Jurnal Basastra, 1(3), 463-477.

Indrakusuma, A.H. (2016). Model Work-Based Learning sebagai Kemitraan untuk Persiapan Lulusan Perguruan Tinggi Memasuki Dunia Kerja. Jurnal Ilmiah Pendidikan Informatika. 1 (1) 32.

Mundziroh, S., Sumarwati, Saddhono, K. (2013). Peningkatan Kemampuan Menulis Cerita dengan Menggunakan Metode Picture and Picture pada Siswa
Sekolah Dasar. Jurnal Basastra, 2(1), 1-10.

Sari, N. A., Saddhono, K., Suyitno. (2014). Peningkatan Kualitas Pembelajaran Menulis Puisi dengan Metode Field Trip pada Siswa SMP. Jurnal Basastra, 1(3), 540-550.

Saddhono, K. (2012). Kajian Sosiolinguistik Pemakaian Bahasa Mahasiswa Asing dalam Pembelajaran Bahasa Indonesia untuk Penutur Asing (BIPA) di Universitas Sebelas Maret. Kajian Linguistik dan Sastra. 24 (2) 178.

Saddhono, K. (2006). Bahasa Etnik Madura di Lingkungan Sosial: Kajian Sosiolinguistik di Kota Surakarta. Kajian Linguistik dan Sastra. 18 (34) 3.

Sukmadinata, N.S. (2009). Metode Penelitian Pendidikan. Bandung: Remaja Rosdakarya.

Suyono, dkk. (2015). Cerdas Menulis Karya Ilmiah. Malang: Penerbit Gunung Samudera. 


\section{LAMPIRAN}

Judul Buku : Assesmen Kualitas Tanah

Pengarang : Prof. Dr. Ir. Purwanto, M.S., Dr. Ir. Supriyadi, M.P., dkk

Instansi $\quad$ : Program Studi Ilmu Tanah Fakultas Pertanian UNS

\section{Kalimat Sebelum Disunting}

Pada tahun 1960an, penelitian diusulkan pada pengembangan praktek pengolahan tanah konservasi dan pada tahun 1980an, sistem tersebut diadopsi secara luas di seluruh wilayah. Pengolahan tanah konservasi dan peningkatan penggunaan pupuk mengijinkan untuk budidaya intensif yang lebih. Meningkatnya kandungan karbon organik diperkirakan memakan biaya 1-4 \$ /ton/tahun (Smith et al.,2000). Beberapa sifat biologi tanah juga meingkat melalui budidaya secara intensif. Ini termasuk di dalamnya meningkatnya aktivitas mikrobia, biomassa mikrobia dan nilai mineralisasi $\mathrm{N}$

\section{Kalimat Sesudah Disunting}

Pada tahun 1960-an, penelitian diusulkan pada pengembangan praktek pengolahan tanah konservasi dan pada tahun 1980-an, sistem tersebut diadopsi secara luas di seluruh wilayah. Pengolahan tanah konservasi dan peningkatan penggunaan pupuk mengizinkan untuk budidaya yang lebih intensif. Meningkatnya kandungan karbon organik diperkirakan memakan biaya 1-4 \$ /ton/tahun (Smith, et al. 2000). Beberapa sifat biologi tanah juga meingkat melalui budidaya secara intensif. Termasuk di dalamnya meningkatkan aktivitas mikrobia, biomassa mikrobia dan nilai mineralisasi $\mathrm{N}$. 

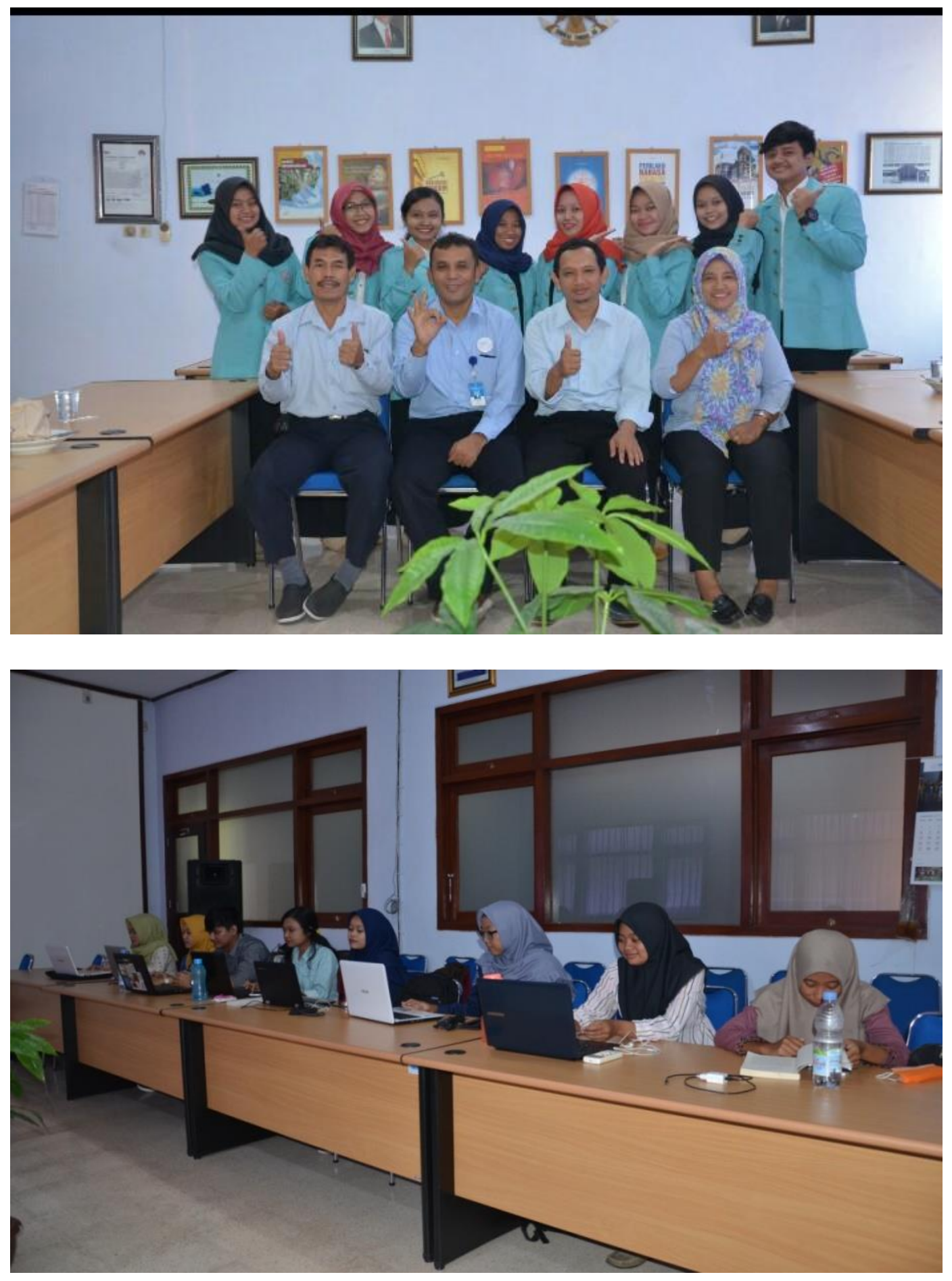